\title{
Managing Competition with China. Proposal of an Operational Model for SMEs
}

\author{
Roberto Panizzolo \\ Department of Management and Engineering School of Engineering, University of Padova, Padova, Italy \\ *Corresponding Author: roberto.panizzolo@unipd.it
}

Copyright (C) 2013 Horizon Research Publishing All rights reserved.

\begin{abstract}
Most of the Western Companies, in the last years, have been facing a tough competition against manufacturers based in developing countries, especially in China. How to face the Chinese competition is an open and relevant issue. This paper aims at giving a contribution to the on-going debate proposing an operational model which might help many SMEs to gain a stronger competitive position. The proposed model can be considered as a rationalization and generalization of an approach to change successfully applied by the author in the last fifteen years in over 30 small and medium enterprises. As to the target, this model has been designed primarily around those SMEs characterized by one or more of the following characteristics: no strong brands, operating in price-driven markets and with products/processes which cannot benefit significantly from investments in R\&D. The proposed operational model is based mainly on three distinct leverages: minimization of the order lead time, elimination of constraints about the minimum order quantity and ability to manage customized, ad-hoc products. In the paper, much attention is devoted to the complex topic of the feasibility of the proposed model. In doing this we make use of a case study. Such a case study is paradigmatic under two remarkably important standpoints: first it backs the applicability of the operational; second, it allows to evaluate what, in practice, has proved to be particularly crucial for the firm and to analyse critically the most relevant lessons learned casting light on the critical success factor for the implementation of the proposed model.
\end{abstract}

Keywords China, Competition, Operational Model

\section{Introduction}

Most of the Western Companies, in the last years, have been facing a tough competition against manufacturers based in developing countries, especially in China. It is widely recognized that Chinese manufacturers can easily compete against their western counterparts thanks to a concatenation of factors, including: very low cost of labour, ability to manufacture a very wide range of products, significant efforts towards the research and development of new, state-of-the-art technologies. Furthermore, the violation of the intellectual property and the lack of western-like safety, environmental and labour legislation further increase the competitive advantage of these firms.

How to face the Chinese competition is an open and relevant issue. This paper aims at giving a contribution to the on-going debate, proposing an operational model which, in the authors' opinion, might help many firms to gain a stronger competitive position.

The proposed model can be considered as a rationalization and generalization of an "approach to change" successfully applied by the author in the last fifteen years in over 35 small and medium enterprises. Primary objective of this research work is to present the main characteristics of this model and to analyse its pros and cons, casting light on its applicability and the potential benefits. In this sense, we make us of a case study that can be considered paradigmatic of the situation. The case study is an essential element of the present work, as it allows to analyse some of the most critical issues associated with the proposed model. In the presentation of the case study a special focus will be placed on the critical success factors for the implementation of the model, as well as on the main lessons learned.

As to the target, this model has been designed primarily around those Small and Medium Enterprises (SMEs) characterized by one or more of the following characteristics:

- no strong brands;

- operating in price-driven markets;

- operating with products/processes which cannot benefit significantly from investments in R\&D.

In order to understand the possible impact of the proposed approach, first an analysis focused on the capabilities and potentialities of the emerging countries has been done. Such analysis is by no means intended to be a comprehensive picture about China and the other developing countries: the theme would be extremely complex, moreover a wide and valuable literature is available (see, for example Chow [1] and Terrill [2]). On the contrary, it is functional to analyse some of the most relevant aspects of the approach herein proposed. 


\section{Who is China?}

Under the term "developing countries" a wide selection of countries and areas worldwide could be listed, located in regions as different as Asia, South America, Africa and Eastern Europe. Considering the on-going debate, China will be analysed only, as it can be considered, under many different viewpoints, one of the most subtle and immediate threats for western economies.

A brief analysis of China will be presented, focusing on three themes:

- the cost of the labour;

- the potentialities of China;

- what China cannot (and will never be able to) do.

\subsection{How Much is Labour in China?}

This question is simple, but the answer very complex. Chinese manufacturers are widely known for their ability to produce items, even high quality ones, at costs which are a fraction of the western ones; nevertheless, getting dependable information about the real cost of the labour in China has proved to be tricky, both because of the heterogeneity of the labour market in the country, and because of the lack of reliable official statistical sources.

In her work of 2004, Banister [3] has performed an estimate of the labour cost in China for the U.S. Bureau of Labour Statistics. Her results can be summed up as follows:

- average labour compensation in the urban areas: 1.06 \$hour

- average labour compensation in the rural areas: 0.45 \$hour

- average weighted labour compensation: $0.65 \$$ hour

It must be observed that the aforementioned values are affected by considerable uncertainty; moreover, the considerable growth rate for the salaries in China (in the urban manufactures, from 1998 to 2002, there has been an overall growth 57 per cent), as well as the enormous social and economical differences among different regions, result in unavoidable relevant error bands. In more recent years, Banister and Cook [4] meticulously construct estimates of hourly labour compensation in Chinese manufacturing. They report a 100 per cent increase in Chinese hourly compensation, measured in yuan, between 2002 and 2008 and contrast it with the 19 per cent increase in US hourly compensation over the same period. The rise of hourly labour compensation in Chinese manufacturing is confirmed by many other authors. In a very interesting paper, Hongbin et al. [5] state that in 1978 the average Chinese urban worker was making \$1,004 (in 2010 dollars). Now, that same worker is making $\$ 5,487$.

Notwithstanding China's unit labour costs have increased both absolutely and relative to US and Europe unit labour costs, China will maintain labour cost advantage in foreseeable future. In 2009 average hourly compensation costs were only $\$ 1.74$, far below those of many of its East Asian neighbours such as Japan (\$30.03), the Republic of
Korea (\$15.06), and Singapore (\$17.54) [6]. It is an exaggeration to say China's labour costs will catch up with the U.S. and European countries in short term. The numbers reported are very useful to understand the order of magnitude of the Chinese manufacturers: indicatively, labour in China is about 15 times cheaper than in the USA, and similar considerations can be done for the European countries.

How to interpret such numbers? The first thing to observe is that China is a country which is transitioning towards a western-like economical model. There is wide agreement on the thesis that the development of Chinese economy will gradually bring salaries and prices to levels similar to those currently experienced in developed countries. In details, the analysis of what has already happened in other Asian countries (Japan, South Korea, Taiwan, just to name a few) leads many analysts to think that China could evolve following the so-called "Flying Geese" model [7,8], which depicts the evolution of underdeveloped countries as the passage from basic and poor manufactures to an industrial system based on technology and leading-edge know-how, favoured by an increasing presence of foreign direct investments, and accompanied by a simultaneous rising of manufacturing costs, prices and salaries.

What nobody seems to be able to predict at the moment are the "times for transition": the flying gees model gives a qualitative, not a quantitative description of the phenomenon; it must also be observed that the extreme complexity of the processes associated with such a transition makes it impossible to derive some numbers from what has happened in other countries, for instance in Japan. What seems reasonable to think about China is that it will take a considerable number of years to reach a stable economical context: it is an enormous country, both geographically and demographically.

Last, but not least, important questions are pending about the "modes" of the transition. The country is involved in a very delicate phase of economical, political and social reforms, and great uncertainty exists about this dimension of the transition [9].

\subsection{The Potentialities of China}

China is often depicted as a country basing its current economical success on low-cost manufactures, but scarcely developed - and practically out of the market - in all those sectors requiring state-of-the-art technologies and/or advanced business models.

A much less simplistic, and arguably much closer to the reality, picture about the real potentialities of China has been proposed by Segal [10], Chen and Yao [11] and Schmitt [12].

In these works, a comparison between the USA and China is performed, casting light on the most advanced technologies currently available, including those of high national strategic relevance (such as supercomputers, software engineering, technologies for the defence industry). The analysis highlights that China is all but an underdeveloped country: it is an increasingly-important 
player in high-tech, thanks to a terrific mix of:

- strong investments in Research and Development (R\&D);

- large number of scientists and engineers of Chinese origin, who have studied at top universities and research centres in the USA, and who can now find very favourable conditions to come back to their home Country.

Alongside domestic R\&D, foreign, direct investments and technology transfer are important avenues for China's economic development and for bridging the technology gap with the OECD nations [13-15].

\subsection{What China Cannot Do?}

Proceeding by exclusion, the only thing that China seems to be far from doing is to reduce the physical distances from the western markets.

Exporting goods from China to Europe, or to the USA, is mainly done by sea shipping, and requires long times: indicatively, the average transportation time between Italy and China (Beijing) is around 30 days, while between Germany (Hamburg) and China (Beijing) is 40 days.

Transportation times might be significantly lowered by airfreight, but there are important reasons backing the idea that it will not be a practical alternative to sea freight on a large scale. Precisely:

- airfreight is much more expensive than sea freight, so it is economically convenient for those products with high value/volume or value/weight ratios only;

- despite the considerable growth that airfreight is experiencing, it must be observed that it freights just a small fraction of the overall international volumes, so it is not supposed to become a general-purpose alternative to sea shipping in the mid- and long-term.

As a consequence, the only real, intrinsic advantage that the western manufacturers have over Chinese ones is given by the shorter distance from the markets, and consequently by the lower delivery times. Sea freight has at least another important consequence on Chinese industry: the minimum quantity for the orders are generally very large, so as to reduce the impact of the transportation costs as much as possible.

\section{How to Deal with China?}

The Chinese expansion on western markets is considered a serious menace for the economic growth of most western countries; the debate about the possible solutions to increase the competitiveness of western companies is on-going, and a variety of different perspectives and proposals can be found in the specialized literature, as well as in the press.

Focusing on the debate currently on-going in Europe, some of the most discussed proposals will be presented and analysed critically. Such analysis is not a complete and accurate one; its scope is to underline their key points and limitations.

\subsection{The Cost-based Competition}

Considering the present difference in the cost of labour between China and the other western countries, it seems quite obvious that at the present basing the competition on the cost reduction is unreasonable. While it might be reasonable for a firm to reduce its costs by some per cent units, the idea of reducing them to $1 / 15$ th does not make any sense.

\subsection{The R\&D-based Competition}

The idea of differentiating western productions from Chinese ones by means of strong injections of research and development (on the products and on the processes) is highly debated, also at a political level, and is often referred to as "the" solution to competitiveness. Nevertheless, it is the authors' opinion that such ideas, even though highly publicized, have not been seriously stress-tested yet.

Firstly, it must be observed that not all the firms can get significant advantages over R\&D activities: the markets and the specific characteristics of the product strongly affect the convenience and feasibility of such measures.

Secondly, there is no guarantee that technology and know-how can be a winning strategy to differentiate from China. As it has already been observed, China is devolving great efforts to attract key experts from other countries, is investing a growing amount of resources into $R \& D$, and is also benefiting from massive external investments done by high-tech companies [16-18].

It is also important to consider the rising investments that many developing countries are doing. China has passed from a 0.6 per cent GDP in 1996, to 1.5 per cent GDP in 2005; considering that the GDP in developing countries like China is growing at a rate greater of that of industrialized countries, the absolute efforts that China is doing in R\&D activities are growing at an incredibly fast pace. From these numbers it seems reasonable to predict that this country in a very near future might become highly competitive also in leading edge technologies and innovations.

\subsection{Competition by Delocalization}

Transferring the most labour-intensive processes towards countries like China has been a pretty common strategy in the last decades, and in many cases it has proven to produce good results, mainly in terms of cost reduction [19]. Yet, in the authors' opinion, it might be dangerous to think of delocalization as a hassle-free universal option, for at least three important reasons:

- firstly, delocalization means having a company split into at least two physically distinct parts: the administrative heart, usually based in a western country, and the manufacturing sites, based in developing countries. When the entrepreneurial way of thinking will have taken place in what today are developing countries, what might prevent local people to start and run manufactures absolutely identical to the western ones, where also the administrative costs are strongly reduced? And where the very small physical 
distances among the functional areas of the firm might allow for the adoption of sophisticated business models?

- who can bet on delocalization? Not everyone: a very large number of today's small and medium enterprises (SMEs) were born as subcontractors for larger firms; according with data from the European Commission, SMEs account for around 80 per cent of the total GDP of the EU, so they are a very important presence in the European context. For most of these SMEs delocalization is not a profitable alternative, especially because many Chinese manufacturers act as subcontractors themselves in the same markets as the SMEs'.

- considering the impact of delocalization under a macroeconomic point of view, great concerns arise about its sustainability: a massive delocalization might create, especially in the short term, very high rates of unemployment, with complex social issues to be solved. In particular, what is not sufficiently stressed in the on-going debate is that while reconverting an existing business to something different takes long times (moreover without guarantees that this re-conversion will ever take-off), moving the production plants to a different country has an immediate and certain impact on unemployment.

Moreover, recent trends and changes in companies' production relocation and back-shoring behaviour against the background of the global economic crisis highlight that that not only the relocation of production to emerging countries, but also the back-shoring of once offshored manufacturing capacities to the home base is a relevant phenomenon. Particularly export-intensive companies tended recently towards (re-)concentrating of their production capacities, trying to exploit the benefits of higher capacity utilisation and a superior relation of variable costs to fix costs at their existing locations. These findings strongly recommend a revision of established decision-making schemes for production relocations based on pure cost efficiency considerations [20].

\subsection{Competition Based on the Copyright and Intellectual Property Protection}

The practice of violation of intellectual property by Chinese Companies is well known, and a harsh debate is still ongoing on these themes. A large part of the entrepreneurial world believes that specific political measures against the phenomenon would be the most effective aid to competitiveness. Counterfeit, in particular, is considered to be doubly harmful for Western firms:

- on the one side, it illegitimately pulls market share off the western firms;

- on the other side, it may bring damage to the brands: qualitatively-poor products coming from low-cost manufacturers and sold as if they came from prestigious firms, or from specific geographic areas, have obvious negative consequences on the consumers' preferences.

It seems relevant to observe two things:

- there are industrial sectors (e.g. shoes and high-end garment manufacturers) which could get benefits if counterfeit would disappear, but for the vast majority of the manufacturers competition is based on parameters like quality, price and service. For all of them, counterfeit and violation of intellectual property have a negligible impact on competitiveness.

- apart from that, great concerns exist about when and how China will enforce the protection of copyrights and patents. Formally, Chinese legislation recognizes and protects the intellectual property, yet the application of the laws, and the penalties in case of violations, are so bland that no practical protection is guaranteed [21-23].

\subsection{The Non-competition: Limitations to Trades}

The competition between China and western countries is strongly asymmetric, due to the enormous differences between the two industrial, social and political contexts. In such conditions, many economists believe that specific trade limitations such as quantity limits (quotas), price limits, embargoes, and license requirements might have positive effects on the economies of the western countries, because they might act - when properly implemented - as a kind of "compensation" for the existing differences.

The debate on these themes is particularly harsh, and no agreement exists about the overall impact that such measures may have. More specifically, concerns are about the impact of such measures on the economies of the different countries, as well as on the political relations between China and the western countries.

An in-depth analysis of these theme would be extremely complex, and would go much beyond the limits and the scope of the present work. Nevertheless, in the authors' opinion it seems important to note that protectionist measures should not be considered as "the" solution to the lack of competitiveness, for at least two reasons. First of all, protectionism cannot be applied on a large scale. According with the principles of the European Union, for instance, limitations to the trades can be applied to a very limited subset of products only, so such measures are unlikely to be considered as a general solution to the lack of competitiveness of most western firms.

Secondly, as it as been clearly underlined by several analysts, competitiveness is something that comes mainly from the firms, not from political actions to support the enterprises. Backing the idea that the solution to the competitiveness problems comes from political actions might have a highly negative impact on the entrepreneurial world, and would restrain the quest for innovation, as well as the development of the business.

This brief overview of some of the possible solutions to increase the competitiveness of western companies against Chinese manufactures is synthesized in Table 1.

\section{A Different Operational Approach}

The preceding analysis has pointed out that the western 
firms have two important and durable advantages over the Chinese ones:

- shorter delivery times,

- closer proximity to the western markets.

The operational model proposed in these paper is all about turning these physical constraints of the Chinese manufacturers into a source of competitive advantage for the western manufacturers.

The proposed operational model is based mainly on two distinct leverages:

- minimization of the order lead time;

- elimination of constraints about the minimum order quantity.

These leverages might be supported, when possible, by:

- ability to manage customized, ad-hoc products.

Why should one firm bet on the lead time reduction and on the elimination of minimum order quantities?

It is easy to guess that such a strategy is neither driven by the will to reduce the costs, nor by the optimization of specific functional areas of the firms. Needles to say that efficiency and profitability are still important constraints for the firms (and they cannot but be, since the scope of any entrepreneurial activity is, by definition, the creation of a profit); the key point here is that the optimization of the costs is a constraint, and not the target of the business strategies.

In the proposed approach, a sustainable form of competitiveness arises from:

- the understanding of some relevant, mostly unexpressed, needs of the customers;

- the focus on specific, and possibly unique-in-the-market, capabilities that a firm can develop to answer these demands.

As it will be explain in the following paragraphs, an extreme flexibility on product variety, lead time and order quantity allows a supplier to "protect" its customers from a considerable number of business risks: this comes into the possibility to adopt much higher prices (hedging risk has a price), and also to capture all those customers that are severely affected by risk-related constraints.

Let us consider, without any loss of generality, a manufacturer whose customers are selling points. In principle, the life of a selling point is organized around two distinct moments:

- the acquisition of the goods;

- the selling of the goods.

Apart from rare cases, there is no simultaneity between the acquisition and the selling of the goods: the selling point usually orders in advance what is expected to be sold in the future, and in doing this it commits to pay for the goods.

Table 1. Different competitive models to increase the competitiveness of western companies.

\begin{tabular}{|c|c|c|}
\hline Competitive Model & Goal & Weaknesses \\
\hline $\begin{array}{l}\text { Competition based } \\
\text { upon Research \& } \\
\text { Development and } \\
\text { Technology }\end{array}$ & $\begin{array}{l}\text { Differentiate western } \\
\text { productions from } \\
\text { Chinese ones by means } \\
\text { of strong injections of } \\
\text { research and } \\
\text { development (on the } \\
\text { products and on the } \\
\text { processes) }\end{array}$ & $\begin{array}{l}\text { - not all the firms can get significant advantages over R\&D activities: the markets } \\
\text { and the specific characteristics of the product strongly affect the convenience and } \\
\text { feasibility of such measures; } \\
\text {-there is no guarantee that technology and know-how can be a winning strategy to } \\
\text { differentiate from China. China is investing a growing amount of resources into } \\
\text { R\&D, and is also benefiting from massive external investments done by high-tech } \\
\text { companies. }\end{array}$ \\
\hline $\begin{array}{l}\text { Competition by } \\
\text { delocalization }\end{array}$ & $\begin{array}{l}\text { Transfer the most } \\
\text { labor-intensive } \\
\text { processes towards } \\
\text { developing countries }\end{array}$ & $\begin{array}{l}\text { - complexity in managing a company split into at least two physically distinct } \\
\text { parts: the administrative heart based in a western country and the manufacturing } \\
\text { sites based in developing countries; } \\
\text { - for a very large number of (SMEs) born as subcontractors for larger firms } \\
\text { delocalization is not a feasible and profitable alternative; } \\
\text {-a massive delocalization might create, especially in the short term, very high } \\
\text { rates of unemployment, with complex social issues to be solved. } \\
\text {-recent trends and changes in companies' production relocation and back-shoring } \\
\text { behavior against the background of the global economic crisis recommend a } \\
\text { revision of established decision-making schemes for production relocations based } \\
\text { on pure cost efficiency considerations }\end{array}$ \\
\hline $\begin{array}{l}\text { Competition based } \\
\text { on the copyright } \\
\text { and intellectual } \\
\text { property protection }\end{array}$ & $\begin{array}{l}\text { Protect western } \\
\text { companies from theft } \\
\text { of intellectual property } \\
\text { and counterfeit brands }\end{array}$ & $\begin{array}{l}\text { - for many manufacturers counterfeit and violation of intellectual property have a } \\
\text { negligible impact on competitiveness which is based on parameters like quality, } \\
\text { speed, service and product differentiation; } \\
\text {-great concerns exist about when and how China will enforce the protection of } \\
\text { copyrights and patents. }\end{array}$ \\
\hline $\begin{array}{l}\text { The } \\
\text { non-competition: } \\
\text { limitations to trades }\end{array}$ & $\begin{array}{l}\text { Use specific trade } \\
\text { limitations in order to } \\
\text { protect western firms }\end{array}$ & $\begin{array}{l}\text {-can be applied to a very limited subset of products only; } \\
\text {-might have a highly negative impact on the entrepreneurial world, and would } \\
\text { restrain the quest for innovation, as well as the development of the business. }\end{array}$ \\
\hline
\end{tabular}


The most relevant and typical issues a selling point must face can be summed up as follows:

- financial risk: ordering in advance means "actual costs against expected profits". In other words, it means that the selling point has to pay for the goods, independently (or almost independently) from what it will actually sell.

- market risk: in highly dynamical and volatile markets, where the preferences of the customers change frequently, a selling point must bet on things like the customers' preferences, fashions and trends.

- minimum order quantity: most suppliers do no accept orders under a specific minimum quantity. This might imply that the selling point cannot match exactly what it expects to sell with what it can order.

- reorder: what happens when a selling point realizes that it has been too prudent with its purchases? In many cases the selling point has just limited margins to reorder, and this turns into the inability to fully exploit all the potentialities of the market.

Arguably, the "ideal supplier" of a selling point would be the one allowing to do as follows:

- goods are ordered when they are sold, or immediately before selling;

- reorder is possible at any moment;

- there are no limitations in the order quantities, also for the reordering.

The idea behind the present operational model is that the western manufacturers should build their competitiveness on such capabilities, for a number of reasons:

- firstly, under specific conditions that will be shown, Chinese manufacturers cannot meet such specific requests. For their intrinsic characteristics, Chinese manufacturers might be able to sell even high quality products at amazingly low prices, but they cannot guarantee flexibility of products, lead time and quantity;

- secondly, allowing the selling points to order what they need and when they need means gaining the possibility to adopt higher prices, basically because such a flexibility allows the selling point to reduce the financial and market risks.

For the western manufacturers, implementing such an ambitious strategy would mean maximizing the intrinsic distance and time advantages they have over the Chinese competitors; it would mean working in a niche market that pays great attention to the reduction of the business risks, intrinsically free from competition by the low-cost manufacturers, where a higher price is justified by some kind of a "risk protection service".

Furthermore, it seems worth noting that in highly dynamical markets, like the present ones, a strongly reduced time-to-market, combined with strong flexibility, might allow the western firms to drive the market as far as styles and trends, thus positioning themselves in a stronger position. The ability to offer customized products would further improve the competitive advantage. The starting point is the customer, with its open questions and its expectations; a winning strategy might come from a radical market repositioning, based on a new way of looking at the customers' expressed or unexpressed needs. Striving to satisfy unsatisfied customers' needs is the starting point of the proposed operational model; the different risks that the customers must deal with are the parameters to work on, and the proposed forms of flexibility are the innovative leverages in the quest for competitiveness.

\subsection{Is That Feasible?}

An important theme which has not been addressed so far is about the feasibility (or, alternatively, the profitability) of the proposed operational model.

A first profile of feasibility is related to the short reaction times: the attention is caught both by the issues related to the manufacturing processes, and by the challenges associated with the management of such new complexities in terms of planning, information management and exception handling.

A second, but definitely not less important element to consider, is profitability, that is to say the cost-to-service ratio. Hedging most of the selling point risks allows the manufacturer to rise the prices of its products (the risk has a cost for the selling point). The question is: how much higher? In other words, are the additional costs the manufacturer must bear to implement the operational model compensated by the higher prices the market is willing to pay, or not?

Third, but not less important, it must be observed that it is not just a matter of "price and cost of the risks": the perspective of a selling point, as well as of a small company, is not explainable just in terms of "average price of the risk". In most cases, the exposure to a certain degree of risk might simply be unbearable for a small company, even though "on average" that level of risk might lead to a valuable "average profit". In other words, hedging the risks might have a much higher impact on very small companies and selling points than what might be forecasted just looking at the average cost of these risks.

Answering these questions is all but trivial: expectably a precise response can only come from the analysis of the specific context, from the market, and above all from the specific actions that the firm has planned to implement. Despite the practical impossibility to draw up a list of quantitative and univocal critical success factors, in the authors' opinion the model might find practical application in a wide range of contexts, maybe also combining the proposed strategy with other leverages.

The feasibility will be analysed in particular when proposing the case study: that will be the occasion to describe both the specific actions undertaken by the Company, and to underline those elements which have turned out to be the most relevant critical success factors. Given the intrinsic characteristics of the case study, it is the authors' opinion that the analysis can give relevant indications about the feasibility and general applicability of the proposed model.

\subsection{Fields of Applicability}


Every operational model, understandably, has its own field of applicability; the present one has been developed thinking of a firm with the following characteristics:

- a large catalogue of products, hopefully characterized by a relevant presence of customizable, non standard or even custom-made products;

- customers which can get a significant economical advantage from flexibility, speed of response and elimination of minimum order quantity.

As to the catalogue of products, it is evident how flexibility and speed of response are negligible advantages in static markets characterized by very low volatility and changes over time: in such contexts the Chinese manufacturers might easily compete in the western countries by means of local wholesalers, fully exploiting their relevant cost advantages. On the contrary, the proposed model finds its ideal application in all those contexts where either the variety of the products or the dynamicity of the market make the creation of large stocks of goods not particularly attractive or feasible.

The other key element is the "customer": the present model can find valid application as long as flexibility and speed of response are felt (or can be felt) by the customers as significant advantages.

It seems worthy to observe that specific approaches to the market might be put in place to maximize the impact of the proposed strategy. A significant example might be moving from a very traditional selling chain model like manufacturer->wholesaler->selling point->client to a scenery like the following one manufacturer->selling point->client or even to a highly streamlined approach like manufacturer $->$ client.

In the proposed scenarios, despite of the fragmentation of the client base that surely increases the complexity of the business, the firm can achieve two relevant forms of competitive advantage over the competitors:

- the possibility to meet the needs of the selling points and/or of the final clients in terms of reduction of the risk and increase in the speed of response;

- the second advantage is the possibility to avoid the intermediate steps from the manufacturer to the final customers, thus adding price margins.

It is important to observe that, if a Company has very little constraints in terms of minimum order quantity and lead time, it has very little need for wholesalers and selling points, as well. In terms of competitiveness this would have a very favourable impact on the western Companies, as avoiding the intermediate passages drastically reduces the cost advantages of the Chinese manufacturers over the western ones. In such a context, the reduction of the lead times and of the minimum order quantities could be a very interesting option also for those firms operating on relatively static markets. The relevant characteristics of the operational model herein proposed are outlined in Table 2.

The proposed model can be considered as a rationalization and generalization of an approach to change (aimed at increasing the competitive ability of a firm) successfully applied by the author in the last fifteen years in over 35 small and medium enterprises situated in the North-East of Italy. This area is one of the most industrialized in Europe and has seen tremendous economic growth in the $70 \mathrm{~s}, 80 \mathrm{~s}$ and part of $90 \mathrm{~s}$.

Most of the companies in this area are organized in the well-known industrial districts and are characterized by no strong brands and operate in price-driven markets with products/processes which can not benefit significantly from investments in R\&D.

A large number of these companies have been deeply affected by competition with emerging countries and many of them have had to rethink their competitive model.

In the following, the attention will be focused on the complex topic of the feasibility of the proposed model. In doing this we make use of a case study that can be considered paradigmatic of the situation. The case study is particularly relevant not only because it backs the applicability of the operational model but especially because it:

- allows to evaluate what, in practice, has proved to be particularly critical for the firm and to analyse critically the most relevant lessons learned;

- casts light on the critical success factor for the implementation of the proposed model.

Table 2. Key characteristics of the proposed operational model.

\begin{tabular}{|c|c|}
\hline Goals & $\begin{array}{l}\text { - minimization of the order lead time; } \\
\text { - elimination of constraints about order } \\
\text { quantity; } \\
\text {-offering of highly customized } \\
\text { products. }\end{array}$ \\
\hline Competitive profile & $\begin{array}{l}\text { - production made on a "to order logic" } \\
\text { - accurate definition of a reliable } \\
\text { delivery date; } \\
\text { - large catalogue of products, } \\
\text { characterized by a relevant presence of } \\
\text { customizable, non standard or even } \\
\text { custom-made products; } \\
\text { - customers which can get a significant } \\
\text { economical advantage from flexibility, } \\
\text { speed of response and elimination of } \\
\text { minimum order quantity. }\end{array}$ \\
\hline $\begin{array}{l}\text { Competitive } \\
\text { context }\end{array}$ & $\begin{array}{l}\text { - low entry barriers; } \\
\text { - absence of strong brands; } \\
\text { - price-driven markets; } \\
\text { - reduced relevance of R\&D due to } \\
\text { mature and well known products and } \\
\text { technological processes } \\
\text { - absence of trade limitations. }\end{array}$ \\
\hline
\end{tabular}

\section{The Case of Gridiron S.p.A}

The case study herein presented is that of Gridiron S.p.A., a small enterprise specialized in the production of technical gratings, drain channels with grids, fencing and manholes.

Born as the evolution of a craftsman like activity started in 1979 by the founding partners, Gridiron S.p.A. has experienced a constant and relevant expansion throughout 
the years, leading it to become a well-established player in its market.

In numbers, Gridiron S.p.A. is characterized by:

- production facilities spread over five areas, for a total of $30,000 \mathrm{~m} 2$;

- 150 full-time employees;

- gross revenue of $28 €$ million.

Since the second half of 90's Gridiron S.p.A. started to study the risks associated with the growing presence of low cost manufacturers from developing countries; as a result of these analyses, and with the support of external consultants, Gridiron started a long term project whose goal was to ensure a stable and sustainable growth for the coming years. This project was carried out along the following two avenues:

- a study of the external competitive context following the Porter approach [24];

- an analysis of the internal resources and competences in accord with the Resource-Based View Theory [25,26].

In the following paragraphs the operational model and the specific actions put in place by Gridiron S.p.A. will be described. A special attention will also be paid to the analysis of the specific context where Gridiron S.p.A. operates, so as to underline the relevance of the main solutions adopted. The analysis of the actions put in place will also be useful to understand the main critical success factors for the implementation of the strategy.

\subsection{The Context}

The analysis of a market context is a very complex matter, that could not be thoroughly treated within the present work. For this reason, the present analysis focuses specifically on a few selected topics that are particularly relevant for the scopes of the present work.

As a first thing it is important to consider the "product" of Gridiron S.p.A.:

- the materials used for the manufacturing of technical gratings are mainly low-carbon steel, for some specific applications also stainless steel like AISI 304, and more rarely brass. All these materials are extremely easy to find in every country in the world;

- the technological processes involved in the realization of technical grids are mainly electro-forging, hot zincing and metalworking like bending, cutting and drilling. As for the materials, also the processes adopted are very well known around the world.

The ease of manufacturing and the use of technological processes and of materials that are well consolidated industry standards do not create any relevant barriers to the entry of new competitors in the market. It is also important to consider that, given the kind of product, things like the brand, or the "made in Italy" label, do not constitute commercial advantages.

Gridiron's market, as most of the business-to-business markets, tends to be driven by two variables:

- the quality of the products and of the service;
- the final price of the products.

It is interesting to observe, however, how the final price is by far the most relevant parameter in this market: a comparative analysis of the products of different manufacturers has pointed out how the quality standards are overall very high and very close to each other, thus making the price the leading driver of the customers' choices.

In such a context, characterized by very low entry barriers, by absence of well known brands and by a strong role of the final price, it is easy to understand that the Chinese manufacturers can easily play a very big role, leveraging on:

- an extremely low cost of workmanship;

- the very low cost of raw materials, semi finished products and energy;

- the gap with western countries in terms of safety and environmental norms;

\subsection{Towards a Winning Strategy}

Given the threats associated with the competition with the emerging countries the owners of Gridiron S.p.A. decided to bet on a radical market repositioning. Conceptually the idea was to move from the traditional, price-driven market, towards contexts where it could be possible to sell other forms of values, such as an extended customer service, the specific know-how, some unique capabilities. After a careful analysis of different scenarios, the owners and the management of Gridiron S.p.A. identified the following fundamental pillars for their new operational model:

- ability to deliver in extremely short times;

- ability to make profit out of extremely small orders;

- ability to develop and deliver highly customized products, designed around the exact specifications of the customers;

- offering a very wide range of products

In brief, such capabilities where intended to attract the attention of all those customers (especially selling points) not keen on ordering large stocks of goods well in advance compared with the moment when they could have been re-sold; in a sense, the underlying idea was to allow the customers to order what they need, when they need it, and with all the customizations that might be required.

\subsection{The Critical Success Factors}

The analysis of the Gridiron S.p.A. case has pointed out that an essential prerequisite for the operational model to work is a wide understanding and sharing of the operational objectives by all the employees, suppliers and sub-manufacturers of the firm.

More precisely, two specific profiles of cooperation were promoted by the management of Gridiron S.p.A.:

- the internal cooperation, intended as the active involvement of the personnel of the Company towards the long-term operational objectives;

- the external cooperation, intended as the cooperation with the most relevant suppliers and sub-manufacturers.

Cooperation, despite being very important for the success 
of an operational model, has emerged to be not sufficient in itself to ensure the success of such a radical strategy. Two other factors were recognized as extremely important for the successful implementation of the model:

- the development of infrastructures able to support the extremely small reaction times and lead times required;

- the development of ad-hoc, advanced techniques of real-time financial controlling.

These two success factors will be analysed in details, as they are somewhat specific of the operational model proposed.

\subsubsection{Development of Infrastructures Supporting Low Reaction Times}

The easiest way to reduce the delivery times is, as known, making extensive use of large stocks of final products. This approach has relevant drawbacks on the costs, and was definitely not an option for a Company like Gridiron S.p.A., having the ambition to play a relevant role as a manufacturer of highly customized products.

Gridiron S.p.A. has therefore focused on the infrastructures, both technological and IT, as well as on the development of business models enabling flexibility while ensuring profitable operations.

As to process technology, the accent has been on automation. Adopting forms of flexible automation on most of the technological processes was identified as a key step to ensure high quality production and reduced lead times. The specific needs of Gridiron S.p.A., and in particular the very special mix of lead time, product flexibility and quantity flexibility, required the design and development of most of these tools from scratch. These investments in technology, distributed across a few years, have allowed Gridiron S.p.A. to support the operational model in a very significant way.

As to the investments in IT and business models, it is very interesting to observe that very short lead times are a necessary, but not a sufficient condition to ensure the feasibility of the operational model herein described. In brief, working in an extremely dynamical environment imposes non-conventional techniques to maintain an adequate situational awareness about the business; the keyword is "real time", as the timescales of the business, with the proposed approach, are considerably shorter than for a more conventional business.

Focusing on the IT infrastructures implemented by Gridiron S.p.A., the three most relevant actions can be identified as:

- techniques for MPRII Real-Time capabilities: "Real Time MRPII" refers to the ability to evaluate accurately, and within a few seconds, the impact that any events or decision will have on the availability of materials, capacity and financial resources. In the present context Real Time MRPII does not refer to high speed scheduling techniques, but rather to a tool with the ability to simulate in seconds the exact impact that every single possible action (e.g. a new order, a change in a production plan, a change in the bill of material, ....) might have on the company, without approximations, and as soon as the event is edited into the information system. Such a capability must be evaluated in comparison with traditional MRPII systems, characterized by batch, asynchronous process that runs generally once a day, requiring considerable computational times. Real Time MRPII is a key tool Gridiron S.p.A. has adopted to keep its information system fully aligned with its current situation, and as such it is at the core of all those IT infrastructures ensuring an enhanced situational awareness;

- automatic product configuration: an analysis of the internal processes showed that the manual steps in the development of customized products were a relevant bottle-neck in the reduction of lead times for customized products; as a consequence, relevant investments were made to make the product configuration as automatic as possible. Given the peculiarity of Gridiron S.p.A. productions, a software tool was designed from scratch around the specific needs of the Company, in order to optimize some highly specific areas of product configuration. One of the most relevant effects of this tools has been considerably reducing the cost and complexity of custom made products, allowing the Company to expand in a highly specific market where the price is not the most significant driver;

- automation of all the steps going from the customer order to the production: the key concept is that all the steps that do not require some kind of creative thinking should be left to the computers. In Gridiron S.p.A. throughout the years the concept of automation has been continuously refined, following a "test and learn" approach that has gradually led to the implementation of more and more advanced techniques. Currently Gridiron S.p.A. is running a very sophisticated tool allowing a complete automation of all the intermediate steps between the order from a customer and the distribution of the finished products, including the update of the availability of materials and capacity, the analysis of the financial impact, the production of the relevant documents and internal communications. It is relevant to say that while every Company should always try to automated as many processes as possible, this is a potentially harmful process: the very critical profile is the compromise between flexibility and automation, as a massive automation might easily bring a range of relevant constraints within the organisation of a Company. As for most of its key capabilities, also for the automation of the internal processes Gridiron S.p.A. has decided to go for a full custom solution, specifically developed around its evolving needs and characterized by the native possibility to override manually every single activity without impacting all the operations.

\subsubsection{Development of Real Time Financial Controlling}

The ability to deliver in extremely short times (evaluated in a few days) has a very important negative consequence, known as "short-term order portfolio". Short-term order portfolio means that the company, at any moment, has an order portfolio covering a very short time period; in the case of Gridiron S.p.A. this can be evaluated in a very small number of weeks. 
Every Company working in such conditions is exposed to a range of specific risks:

- as a first thing, the activity of the Company is covered just for a limited number of days, hence exposing the Company to relevant market risks;

- situations of lack of orders, or on the contrary of over-loading, can happen very quickly, and this imposes specific forms of highly-reactive controlling to keep the business always under control.

Real time financial controlling is also required by the lack of minimum ordered quantities: in this case specific forms of controlling are required to understand in real time, at the order level, the profitability of the business.

An essential element of Gridiron's advanced financial controlling is an IT tool fully integrated in the information system that can develop in less than one minute a detailed simulation of the future financial flows by date, by order and by bank/account. It is relevant to observe that the financial analysis has some great advantages over the economic analysis from the controlling perspective:

- it can be run at any point in time and using the most up-to-date information, as there is no need to do economic evaluations over a specific period (as required by the traditional economic analysis). The concept is that the forecasting of the future cash flows, if performed correctly, can provide a very early and extremely accurate picture about the Company's ability to generate profits;

- other than being a necessary tool to implement its strategy, real time financial controlling is also widely used to plan very short-term investments of the cash surplus, and to manage very effectively the relationships with the different banks. This has an impact on the Company's income.

\section{Final Comments and Conclusions}

The experience of Gridiron S.p.A. represents a successful case of a business strategy based on:

- ability to deliver in extremely short times,

- without imposing limitations in terms of minimum ordered quantities,

- leveraging on the offer of a wide range of different products, including fully customized solutions.

Gridiron S.p.A. operates in a price-driven sector where the Chinese competition can be extremely aggressive; nevertheless, the relevant lessons learned from the analysis of the case study are that:

- there is a segment of the market that appreciates the risk reductions associated with flexibility of quantity, variety and short lead times. While such forms of risk hedging are somewhat unexpressed by most of the customers, this does not mean that they cannot become powerful forms of added value;

- despite the potentialities associated with such a strategy, it is worth noting that many conditions and prerequisites must exist to ensure the profitability of such a business strategy;

- the experience of Gridiron S.p.A. indicates the importance of the investments on ad-hoc, full custom IT and technological solutions: the most relevant lesson learned is probably that a real innovation comes from state-of-art technologies customized to follow the specific intricacies of each business, to exploit those peculiarities and specific best practices that make every Company unique and, in most cases, highly performing. The small dimensions of Gridiron S.p.A. also suggest that full-custom, state-of-art IT and technological solutions are not a privilege for a restricted number of very large organisations, but can be easily adopted also by a very large base of SMEs;

- last, but not least, the case of Gridiron S.p.A. suggests that the development of long term strategies and the continuous analysis of the external threats, also in the long term, should become integral part of the culture of the SMEs. Gridiron S.p.A. has started thinking of the Chinese menace since the second half of the 90's; this has allowed its management to put in place a series of initiatives that are currently supporting the Company in its quest for competitiveness. The IT and technological infrastructure are integral part to ensure the success of the operational model of Gridiron S.p.A., yet their complexity suggest that such investments can be effectively made on the long term. Looking ahead and understanding the premonitions are key practices whose importance rarely seems to be adequately stressed.

The operational model proposed in this paper focuses on one strategic lever, the improvement of the logistics process. In doing so this study is likely to convey a partial view of what constitutes a comprehensive strategy for success.

It's been said that the proposed model is of interest to a limited group of companies, those, as it has been said, that does not have a strong brand, which operates in price-driven markets and with products/processes which cannot benefit significantly from investments in R\&D.

More generally, it is necessary to frame the debate on the need for boosting competitiveness of the western industrial system within the overall scenario of global competition. Only in this way it is possible to grasp the size of the big changes that are redefining the entire economic paradigm.

From this point of view, a globalized world requires companies to adopt global strategies. This statement takes on two different meanings, both important and complementary. On the one hand it means that no longer exist competitiveness of a domestic nature. The strategic thinking tends to be equal in the entire globe, although not homogeneous, and the excellence can be realized in very different parts of the world.

On the other hand, however, there is not only a comprehensive strategy capable of ensuring excellence. It is necessary to adopt a mix of different approaches depending on the type of company, specificities of the industry in which it operates, the product-service that is offered, etc.

In other words, the innovative logistics strategy examined in the Gridiron case is not the only adoptable. It is specifically for those companies described above. For companies operating in different contexts is important to adopt different strategic levers. Successful companies do not 
focus on a single strategy, but achieve the difficult reconciliation between high differentiation and low costs, through strategic combinations where cost optimization and the search for differential advantage are subject to constant reflection. In this sense, it is of great interest to study the strategic and organizational best practices implemented by successful companies.

\section{Acknowledgements}

The author wishes to express sincere appreciation and gratitude to the management of Gridiron Spa for their appropriate and constructive collaboration.

\section{REFERENCES}

[1] Chow G. C., China's Economic Transformation, Blackwell Publishers Inc., Malden Mass., 2002.

[2] Terrill R., The New Chinese Empire and What It Means for the United States, Basic Books, New York, 2003.

[3] Banister J., Indexes of hourly compensation costs, Monthly Labor Review Online, Vol.127, No.11, 23-31, 2004

[4] Banister J., Cook G., China's Employment and Compensation Costs in Manufacturing through 2008, Monthly Labor Review, March, 39-52, 2011.

[5] Hongbin L., Lei L., Binzhen W., Xiong Y., The End of Cheap Chinese Labor, Journal of Economic Perspectives, Vol. 26, No. 4, 57-74, 2012.

[6] Banister J., China's manufacturing employment and hourly labor compensation, 2002-2009, International Labor Comparisons, Bureau of Labor Statistics, June, 2013.

[7] Akamatsu K., Historical Patterns of Economic Growth in Developing Countries, The Developing Economies, Vol.1, 3-25, 1962.

[8] Kwan C. H., The Rise of China and Asia's Flying-Geese Pattern of Economic Development: An Empirical Analysis Based on US Import Statistics, Nomura Research Institute (NRI) Papers, Vol.52, No.8, 2002.

[9] Walder A. G., Sociological dimensions of China's economic transition: organization, stratification and social mobility, Asia Pacific Research Center (APARC), Stanford Institute for International Studies, 2003.

[10] Segal A., Is America losing its edge? Innovation in a Globalized World, Foreign Affairs, Vol.83, No.6, 2-8, 2004.

[11] Chen J., Yao S. (editors), Globalization, Competition and Growth in China, Routledge, New York, 2006.
[12] Schmitt G.J. (editor), The rise of China: essays on the future competition, Encounter Books, New York, 2009.

[13] $\mathrm{Hu}$ A. G. Z., Jefferson G. H., Jinchang Q., R\&D and Technology Transfer: Firm-Level Evidence From Chinese Industry, The Review of Economics and Statistics, Vol.87, No.4, 780-786, 2005.

[14] Meyer K. E., Sinani E., When and where does foreign direct investment generate positive spillovers? A meta-analysis, Journal of International Business Studies, Vol.40, 1075-1094, 2009.

[15] Whalley J., Xind X., China's FDI and non-FDI economies and the sustainability of future high Chinese growth, China Economic Review, Vol.21, No.1, 123-135, 2010.

[16] Chen X., Sun C., Technology transfer to China: alliances of Chinese enterprises with western technology exporters, Technovation, Vol.20, No.4, 353-362, 2000.

[17] De Meyer A., Technology Transfer into China: preparing for a New Era, European Management Journal, Vol.19, No.2, 140-144, 2001.

[18] Yueh L., Van Reenen J., Why has China grown so fast? The role of international technology transfer, Department of Economics Discussion Paper Series, University of Oxford, 2012.

[19] Nassimbeni G., Sartor M., Sourcing in China - Strategies, Methods and Experiences, Palgrave Macmillan, New York, 2006.

[20] Kinkel S., Trends in production relocation and backshoring activities: Changing patterns in the course of the global economic crisis, International Journal of Operations \& Production Management, Vol.32, No.6, 696 - 720, 2012.

[21] Pattloch T., The new regulations for international technology transfer in the People's Republic of China, International Review of Industrial Property and Copyright Law, Vol.35, No.2, 151-168, 2004.

[22] Deli Y., Insights from the P. R. China of Multinational Intellectual Property Inflows, Bradford University School of Management, Bradford, England, 2004.

[23] Chen L., Linb P., Songd F., Property rights protection and corporate R\&D: Evidence from China, Journal of Development Economic, Vol.93, No.1, 49-62, 2010.

[24] Porter M.E., Competitive Strategy: techniques for analyzing industries and competitors, The Free Press, New York, 1980.

[25] Prahalad C. K., Hamel G., The Core Competence of the Corporation, Harvard Business Review, Vol.68, No.3, 79-91, 1990.

[26] Grant R. M., The Resource-Based View of Competitive Advantage: Implication for Strategy Formulation, California Management Journal, Vol.33, No.1, 114 - 134, 1991. 